\title{
Transplantation Through the Generations
}

\author{
Alberto Castagna, Lisa Mcmonagle, \\ Corien Eeltink, and Sarah Liptrott
}

\subsection{Transplanting the Child}

\begin{abstract}
Biologically, a child is a human being between the stages of birth and puberty. The legal definition of child generally refers to a minor, otherwise known as a person younger than the age of majority (Oxford University Press (Accessed 5th January 2013)).
\end{abstract}

\footnotetext{
A. Castagna

Paediatric Hemato-Oncology and HSC Transplant

Nurse at Paediatric Hematology-Oncology and

HSCT Unit, Ospedale Donna e Bambino - Azienda

Ospedaliera Universitaria Integrata (AOUI) Verona,

Verona, Italy

e-mail: alberto.castagna@aovr.veneto.it
}

L. Mcmonagle, BSc (Hons), MSc, RN

Teenage Cancer Trust Advanced Nurse Practitioner for Teenagers and Young Adults, University College, London, United Kingdom

e-mail: lisa-marie.mcmonagle@nhs.net

\section{Eeltink $(\bowtie)$}

Department of Hematology, Cancer Center

Amsterdam/ VU University Medical Center,

Amsterdam, The Netherlands

e-mail: c.eeltink@vumc.nl

\section{S. Liptrott}

Division of Haemato-oncology, European Institute of Oncology, Milan, Italy

e-mail: sarah.liptrott@ieo.it
The ability to cure children with cancer has radically improved over the recent decades. Today, more than $80 \%$ of children with cancer are cured of their disease (Franklin 2014). This incredible achievement is one of the greatest triumphs in the history of medicine and is the result of numerous factors, including developments in paediatric haematopoietic stem cell transplantation (HSCT). Treatment advances for the sick child have been accomplished in various cancer treatments including chemotherapy, surgery, radiotherapy and HSCT. Whilst these therapies have vastly improved outcomes in childhood cancers, there remains scope for further improvement.

Keywords HSCT • Paediatric

\subsubsection{The Role of EBMT in Paediatric HSCT}

Changes in HSCT approaches are responsible for progress in this particular area. The role and status of transplantation have evolved. It is no longer considered a salvage therapy for patients in desperate circumstances but is now the treatment of choice for many diseases. The history of paediatric HSCT in Europe began in Poland in 1949 (RaszekRosenbusch), with therapeutic transfusion of bone marrow in children with leukaemia and other blood diseases. Subsequent developments in paediatric HSCT were driven on by the creation in 1974, of 
the European Society for Blood and Marrow Transplantation (EBMT). The goal of the society remains to promote all aspects associated with HSCT. Since the launch of the EBMT Society in 1974, several working parties were established, and in 1995, the Board of the EBMT founded the Paediatric Diseases Working Party (PDWP). Shortly after, the registry of the EBMT began to analyse transplant outcomes in children and adolescents increasing our understanding which in turn informed changes and developments in the field. The continuous progressions and evolution of paediatric HSCT in Europe have been resulted in the establishment of HSCT as a standard therapeutic procedure in paediatric haemato-oncology.

The number of children and adolescents undergoing HCST has been steadily increasing since the 1980s. It is clear that close national and international collaboration between HSCT units helps to resolve common difficulties with this complex treatment. The scale of collaboration within the EBMT members is underpinned by the EBMT survey of Passweg et al. (2016) reporting more than 40,000 HSCT per year in 680 centres from 49 countries in Europe and affiliated countries. The report described:

- Transplant rates

- Indications

- Donor type

- Stem cell source

- Conditioning MAC and RIC

- Donor lymphocyte infusions

This report enables us to observe trends and changes in HSCT practice over time. The paper reported 4400 paediatric transplants in 2014 of which almost $75 \%$ are allogeneic. A family member donated cells in 53\% of these (70\% HLAidentical, $29 \%$ non-HLA-identical, $1 \%$ syngeneic) and $47 \%$ of unrelated donor (Table 8.1).

The high proportion of allogeneic transplants in paediatrics is largely due to the characteristics of paediatric diseases that are amenable to transplantation such as haemoglobinopathies, immune deficiencies, immune dysregulation and metabolic diseases.

Furthermore, in paediatric allogeneic transplantation, the leading indication is ALL (26\%), followed by primary immune deficiencies (16\%) and then AML (14\%). Conversely, in the paediatric autologous transplant, the major indications are neuroblastoma (35\%), other solid tumours (31\%) and lymphoma (15\%).

The 2012 EBMT report notes that more paediatric patients receive BM stem cells than PBSC, irrespective of donor type (Passweg et al. 2014).

\subsubsection{Child Growth and Development}

It is important to know and understand the developmental stages of infants and children because appreciation of the ages, stages, common milestones and abilities allows nurses to relate to the children and their relatives appropriately. The knowledge of the normal growth and development equips the nurses to identify any developmental delay. Growth and development are a single process which begins during pregnancy and continues throughout childhood and into adolescence. Growth is a change in the body size and structure, whilst development is a change in the body function.

Table 8.1 Number of paediatric haematopoietic SCTs in Europe in 2014 by donor type

\begin{tabular}{|c|c|c|c|c|c|}
\hline \multirow[t]{2}{*}{ 'Paediatric centres' } & \multirow[t]{2}{*}{227} & $\begin{array}{l}\text { Combined adult- } \\
\text { paediatric centre }\end{array}$ & 118 & & \\
\hline & & Paediatric only centre & 109 & & \\
\hline \multirow{2}{*}{$\begin{array}{l}\text { Number of } \\
\text { transplants }\end{array}$} & \multirow[t]{2}{*}{4400} & Allogeneic & 3279 & & \\
\hline & & Autologous & 1121 & & \\
\hline \multirow[t]{4}{*}{ Donor type } & \multirow[t]{4}{*}{3279} & \multirow[t]{3}{*}{ Family member } & \multirow[t]{3}{*}{1729} & HLA-identical & 1224 \\
\hline & & & & Non-HLA-id & 501 \\
\hline & & & & Syngeneic & 4 \\
\hline & & Unrelated donor & 1550 & & \\
\hline
\end{tabular}




\subsubsection{Child Growth}

Child growth refers to progressive structural and physiological changes in the size of a child body. Physical growth includes gaining full height and appropriate weight and increasing in size of all organs. The measurements of weight, length, head circumference, body composition and tooth eruption aid assessment of normal and standard physical growth (Mona 2015).

\subsubsection{Child Development}

Child development concerns a child's ability to undertake more complex processes as they mature. Child development is subdivided into specific areas:

- Motor

- Language

- Cognitive

- Behavioural and emotional

\subsubsection{The Child and the Experience of Disease}

The child is aware of the condition and often the severity of their disease whatever his age (Badon and Cesaro 2015). This consciousness derives primarily from their perception of the body and wellness state changes but also communicative and relational aspects.

\subsubsection{Hospitalisation}

The child is sensitive to the experience of disconnection that disease imposes. The disease acts as a breaking event in the life of the child and alters the way the body is considered and treated. Hospitalisation changes the physical and relational environment and modifies the emotional climate and the usual style of education.

During the hospitalisation, the child's world is changed; for instance, they are relieved of responsibilities, and many rules disappear or are replaced. They become the target of therapeutic measures, sometimes with little consideration for privacy or confidentiality, and the child becomes separated from their world. If this disconnect remains within the child's limits of tolerance, it is absorbed into their normal development. However, if this disconnect exceeds their tolerance, it results in a traumatic experience and becomes in itself a source of anxiety and distress (Badon and Cesaro 2015).

\subsubsection{Disease Awareness}

A child's disease awareness is determined by the child's own level of cognitive function and experience. These factors impact upon a child's ability to understand the meaning and significance of what is happening. The reactions that a child may exhibit will be governed by:

- Age and stage of intellectual development

- Previous experiences

- Quality of relationships established with reference figures

- Psycho-emotional structure

\subsubsection{Emotional Reactions to Hospitalisation}

The child often does not have the ability to understand the causes and the logic of the events that lead suddenly to being excluded from their family environment, separated from significant figures and entrusted to the care of strangers. The child will tend to experience hospitalisation with a sense of danger that derives primarily from the inability to understand and control the absent parent (Badon and Cesaro 2015).

\subsubsection{Patient, Caregiver and Sibling Donor Experience HSCT}

HSCT is usually an elective, planned treatment. Children who suffer from malignant disease and undergo- transplantation often have experienced previous treatments and hospitalisations for treatment of complications such as fever, pain, mucositis, nausea and vomiting as well as periods of isolation. HSCT is an intensive treatment process and offers the chance of a cure, but at the same time it can generate a range of feelings including fear, isolation and depression. The skills of the child to address the emotional and psychosocial aspects of transplantation depend on their age, 
development phase, cognitive level, individual personality and type of psychological support. The hospitalised child receives important support from their family. Parents are invited to actively participate in the care of their child, and during the period of transplant, a parent or a close family member usually stays with the child for the duration of hospitalisation. The experience of HSCT should not hinder the psychosocial growth of the child and may even aid the promotion of development and self-esteem. Nurses have a principal role in providing emotional support to the child and the family caregiver and can assist the child in understanding their condition and overcoming negative emotions.

\subsubsection{The Paediatric Patient Experience of HSCT}

Paediatric patients undergoing HSCT can experience numerous psychological reactions during hospitalisation and recovery:

- Anxiety

- Depression

- Behavioural issues

- Psychosocial issues (adherence, self-esteem, social competence)

- Post-traumatic stress reactions (Packman et al. 2010)

Many of these concerns arise from lengthy hospitalisations away from home, school and friends, isolation and an uncertain future. These factors contribute to high levels of emotion at admission and are reported to escalate until 1 week post HSCT (Phipps et al. 2002). The paediatric HSCT patient can experience multiple hospitalisations, which can occasionally last up to 1 year or longer depending on the severity of the complications. HSCT and its immediate and late consequences have substantial impact on the child's physical, emotional, cognitive, and social well-being and consequently severely compromise the child's quality of life (QoL).

\section{QoL}

QoL is potentially affected during all stages of HSCT, including pre-transplant, during the acute
post-HSCT time and during isolation and reintegration to life outside the hospital. Pre-transplant predictors of QoL include family functioning and individual resources. It is reported that during hospitalisation, children undergoing HSCT present low baseline levels of QoL. However, QoL improves as early at some months post-HSCT and returns to baseline within some years from HSCT (Tremodala et al. 2009).

\section{Cognitive Impact}

The effect of HSCT on cognitive abilities may differ depending on age at HSCT and conditioning regimens, TBI containing regimes versus nonTBI. The younger the child is at HSCT, the higher the risk for deficits in intelligence quotient, academic achievement, fine motor skills and memory. The child with good cognitive developmental level at the time of HSCT can be at lower risk for cognitive deterioration (Barrera et al. 2007).

\section{Mental Health and Emotional Concerns}

Many paediatric HSCT patients demonstrate stable psychosocial adjustment or return to baseline functioning 1 to 2 years after HSCT. However, psychiatric morbidity in HSCT survivors is reported in some studies as higher than in the general population and appears to correlate with lower educational level and shorter post-HSCT period. Furthermore, shorter time post-HSCT, higher numbers of major infections, high symptomatology score and low educational level are predictive factors of higher psychosocial distress (Tremolada et al. 2009).

Such psychosocial distress is not unique to the immediate post-transplant period. There are concerns later post-HSCT as well. At 1-year postHSCT when many survivors return to school, they function at a lower academic level than what is expected for their age. They can be described by peers as absent from school more, less likely to be chosen as a best friend, less athletic and less attractive, and those who experience extensive periods of isolation may demonstrate development decline in socialisation and communication (Packman et al. 2010). There is a further possibility of long-term emotional and social-behavioural problems. 


\section{Depression and Anxiety}

Depression and anxiety in an ill child can result in disability and morbidity and are associated with psychiatric illness (Chang 2012). Children undergoing HSCT are a high-risk group for developing these problems (Manookian et al. 2014). Contributing factors include:

- Intense medical treatments

- Single room isolation

- Parental concern

- Uncertainty and loss of control

Almost all children report some difficulties during the transplant process such as loneliness, sense of fear and worsening depressive and isolation symptoms (Packman et al. 2010).

\section{- Intense Medical Treatments}

The HSCT in the child can be associated with medical and psychosocial stressor. The main medical stressors identified to the child are medical interventions and treatment side effects. At the same time the psychosocial stressors can be recognise as missing home or social isolation. Therefore, the HCST can evoke in the child feelings of nervousness, sadness and anger.

\section{- Isolation}

It is widely recognised that physical isolation could contribute to increased depressive symptoms during hospitalisation with factors such as strict isolation and specialist care due to decreased immune functioning potential stressors. During this time, their main concerns are separation from their family members, or even from their toys or possessions, inability to attend school or participate in normal social activities. The common experience of all these children is the feeling of loneliness. Reactions include depression, anger, frustration and attempts to 'overcontrol' their life, food and hygiene. The isolation period can be perceived as a loss of freedom and control and an intrusion on privacy. If isolation is extended, due to problems related to HSCT, children can report declines in social competence and self-esteem (Packman et al. 2010).
It is important for the child to benefit from sibling support. This can increase tolerance of difficult conditions encountered during the HSCT and aid progress and recovery. During this time, they can develop deep sibling friendships, fed by a desire to be more helpful especially when the ill sibling feels lonely. When stem cells are donated by one a sibling, the ill child experiences more positive feelings about him/her (Manookian et al. 2014).

\section{- Parental Concern}

There is a close relationship between the child's adaptation to HSCT and the parent's psychological health and comfort (Asadi et al. 2011).

\section{- Uncertainty and Loss of Control}

Transplantation should be viewed as a chance of hope for a healthy future and long-lasting happiness for the child. If he/she maintains this positive attitude being hopeful about his/her recovery, the child can have a positive response from the treatment and overcoming complications (Manookian et al. 2014).

\section{Support and Fostering Healthy Coping Strategies}

As expected, most children experience a sense of fear during their HSCT process. This feeling can be related to a lack of information or understanding regarding his/her condition and conditioning and transplantation process. Providing clear and understandable answers to the child's questions about the illness, treatment and prognosis can help them feel reassured and more relaxed. Information seeking is an important coping strategy for children undergoing to HSCT. Developmental status and psychological state should be considered to enable appropriate communication and provision of information.

Coping strategies used to address a perceived medical or psychosocial stressor may change over time depending on personal factors and context. The child can use several different coping strategies which are often categorised: 
- Approach (i.e. information seeking)

- Avoidance (i.e. distraction or distancing)

- Problem-focused (i.e. problem solving)

- Emotion-focused (i.e. seeking emotional support)

Additionally, Bingen et al. (2012) observed wishful thinking, distraction, cognitive restructuring and social support being used both preand post-HSCT.

\section{Social Support}

Social support is the individual's perception of positive regard from relationships with others, the feelings to being loved, being part of a group, reassurance of self-worth and reliable alliance with others (Barrera et al. 2007). Social support is reported to be the most efficacious, for a child undergoing a HSCT, whether this is from family, friends, teachers, classmates and medical, nursing and psychosocial providers. It is both instrumental and emotional and may be provided directly to the child in the form of hospital visits or via telecommunication (e.g. video calls, phone conversation or texting, online social networking sites and e-mailing). Higher or more positively perceived social support has been identified to be associated with positive adjustment, lower distress and higher self-esteem in paediatric patients undergoing HCST (Barrera et al. 2007).

\subsubsection{The Parent Experience of HSCT}

Asadi et al. (2011) reported in a qualitative study the Parents' Experiences of their Children Bone Marrow Transplantation. The experience of HSCT is an unfamiliar, frightening, worrying and stressful experience for the parents of the child undergoing this treatment. Child-centred reasons include:

- Severity of the disease

- Uncertain prognosis

- Complications and risks

- Isolation of patients

- Long hospitalisation period

\section{Parent-centred reasons include:}

- Family and financial pressures

- Feelings of guilt
- Loneliness

- Hopelessness

- Fear of disease recurrence

- Transplant centre relocation

- Living in two separate households

- Commuting between home and transplant centre

- Other family member's and carer's responsibilities

- Work-related changes

- Lengthy hospital stays

- Parental informed consent for the HSCT procedure

- Medication compliance

- HSCT-related complications

During HSCT, parents develop high expectation about a successful outcome and are afraid of possible failure. The child's condition can cause parental distress, anxiety and depression. Physical, emotional and cognitive exhaustion or burnout in parents may adversely affect their ability to meet the needs of their child. They could be in extreme crisis and be unable to care for their children or perform traditional parental roles and consequently have feeling of hopelessness, concern and guilt. Parental psychological reactions may in turn negatively affect the child. The psychological load on parents continues when the child is discharged from the ward. Burnout in mothers and fathers is associated with the child's number and severity of late effects up to 5 years after HSCT (Norberg et al. 2014). It is recommended that parents of child that underwent HSCT should be followed up and receive specialist psychological support, particularly for those whose child suffers from late effects.

Common coping strategy amongst families is use of social support. Parents' interactions with their support network can alleviate stress and enable parents to adapt. Some parents feel that communication with family members of other patients aids in acquiring information and in sharing of experiences and helped to take control of their emotions to reduce fear and become adaptive (Badon and Cesaro 2015). Caregivers also attempt to cope by actively participating, engaging in and asking questions pertaining to their child's medical illness and the procedures 
involved in helping them. Parents who received cognitive-behavioural stress inoculation training in a group format had lower anxiety scores and higher positive self-statement scores (Packman et al. 2010). They can also increase their coping strategies by interacting with other families who share the same problem.

\section{Creating a Therapeutic Alliance}

Parents and the healthcare team need to unite to form a therapeutic alliance. Parents should be integrated into the multidisciplinary healthcare team as appropriate. The healthcare team's explanations regarding the transplant process can help them to better understand their conditions and, consequently, can alleviate parental anxiety and fear of uncertainty and help to further reducing their emotional burden.

\subsubsection{Sibling Donor Experience in HSCT}

Matched sibling donors are often preferred over unrelated donors due to decreased risk of complications. Most family members find the experience of donation as beneficial, despite some concerns about the donation process itself (Pentz et al. 2014). Sibling donors actively participate in the effort to achieve cure for their sick sibling. They have a dual role; as family members they experience the difficulties of a life-threatening illness of one of their siblings. As donors they are exposed to an invasive medical procedure which adds anxiety, stress and uncertainty and places them in a complex situation (Munzenberger et al. 1999; Williams et al. 2003). When a close relationship exists between siblings, one can more safely assume that the donation will be of psychological benefit to the donor (Vogel 2011). However, sibling donors are at risk of developing emotional disturbances such as post-traumatic stress reactions, anxiety and low self-esteem and can potentially lead to the development of longterm distress responses (Packman et al. 2010). Attention should be paid to the possibility of these issues. During the pre-transplant workup, potential donors may experience anxiety and fear about the processes used to determine donor eligibility as well as during the donation process itself (Bauk and Andrews 2013). Although matched siblings may feel content and proud that they are able to be a donor, the unmatched siblings may feel inadequate or rejected and uninvolved in the transplant process. Once HLA typing has confirmed a sibling match, the workup for most haematopoietic stem cell donors involves determining both the risks to the recipient and the risks to the donor. It is also important to consider that these various tests may be overwhelming to the paediatric donor, and the importance of explaining their necessity cannot be understated. The workup process may have a significant impact on the family. In 2010 the American Academy of Pediatrics published a policy statement on children as haematopoietic stem cell donors. Children may ethically serve as donors if five criteria are fulfilled: 1 . There is no medically equivalent histocompatible adult relative who is willing and able to donate; 2 . there is a strong personal and emotionally positive relationship between the donor and recipient; 3 . there is a reasonable likelihood that the recipient will benefit; 4 the clinical, emotional and psychosocial risks to the donor are minimised and are reasonable in relation to the benefits expected to accrue to the donor and to the recipient; and 5. parental permission and, when appropriate, child assent are obtained. It is also recommended that the donor child will have a donor advocate or some similar mechanism, with expertise in paediatric development that should be appointed for all individuals who have not reached the age of majority (Committee of Bioethics 2010).

The HSCT process can enhance family closeness, improved relationships with the unwell sibling and create a sense of pride and happiness about donating (Vogel 2011). Wiener et al. (2007) found that younger donors focus more on the pain of the donation and tend to experience low self-esteem, anxiety, and depression. Conversely older sibling donors report lower levels of anxiety probably because they are able to think more globally about the donation process.

Studies of physical aspects and the safety of stem cell collection in paediatric sibling concluded that it is a safe procedure even in young children (Pulsipher et al. 2005; Styczynski et al. 2012). There are potential physiological risks and side effects of donation with the most common 
being pain, fatigue and transient changes in the white blood count, haemoglobin and platelet values. In the immediate days following the donation, staff must closely assess the donor for evidence of bleeding, infection and other acute complications of the donation procedure. Feeling responsible for the transplant outcome is of notable concern for sibling donors. Maladjustment and poor coping in sibling donors may be attributed in part to a lack of information about the transplant process (Wiener et al. 2007).

The nurse can have a significant role in decreasing the sibling donor's stress and anxiety about the impending donation. Providing accurate and age-appropriate information about the impending procedure, the nurse may also help the child prepare for the experience and adapt to it more rapidly. This information increases the predictability of frightening medical procedures, thereby increasing the probability of a less stressful experience and a more rapid recovery. The nurse can also create opportunities to express emotion, concerns and questions in order to manage anxiety and guilt, involve parents in the donor's preparation and follow-up to ensure family's communication during HSCT and organise a tour of the hospital and an introduction to staff.

\subsubsection{Centred Nursing Care of Patients and Caregiver's Undergoing HSCT}

Psychological and emotional aspects of the paediatric experience are complex and intricate. Health workers who take care of the sick child should be the privileged listeners of the child and be receptive to the child's point of view creating opportunities to talk.

\subsubsection{The Relationship Between Nurse, Caregiver and Child}

The approach of the paediatric team is strongly characterised by interpersonal and communication methods that are centred on empathic understanding, smiling, patience and gentleness. The relationship between nurses and children, but especially amongst nurses and parents, is difficult to summarise. However, this triangulation involves many mechanisms, roles and functions and impact on different aspects of personality and character.

\subsubsection{Nursing Involvements in Care of Children Undergoing HSCT}

\section{Communication with the Child Undergoing HSCT}

To employ an effective communication, professionals need to improve their listening and observation skills and exercise the ability to transmit ideas and feelings to others.

\section{Information and Reassurance}

It is through age-appropriate dialogue that healthcare professionals can explain to the sick child the sense of what is happening, the need for frightening interventions, recognition and meaning of fears. The child must know that they will never be left alone and nothing will happen that was not first controlled or decided by someone else in whom they are confident (Manookian et al. 2014).

The opportunity for the child to be properly informed allows them to become aware of what is happening to him in his life, to have greater familiarity with hostile hospital setting and be able to work together in their treatment path. Communication about the transplant process between the care staff, child and family can be further complicated by the different opinions with respect to what it is to be explained to the sick child. In general, it is preferred to adopt an attitude that respects the will of the parents, but this can lead to difficulties when it is the child themselves asking or looking for other information. The information, however, allows a reduction of the perception of pain, an increase in the child's compliance and a general improvement of the quality of life in the hospital (Badon and Cesaro 2015). The child who reports more free expression of emotion in their family in turn experiences lower levels of distress throughout the transplant period. Openness and honesty in 
communication in the family environment can encourage the emotional well-being of child and further promote their resiliency after the HSCT procedure is complete (Packman et al. 2010).

\section{Listening}

The ability to listen allows us to establish constructive relations. A real attitude to listening implies the attention, interest, tolerance, understanding and acceptance of the other. All of these are necessary preconditions for the establishment of an open relationship in which it is easier for the child to express and give information about himself. It is useful to encourage the patient to express themselves freely because, in addition to containing their distress, it is possible for the nurse to better understand the organisation of their personality and the defences put into place to cope with the situation (Badon and Cesaro 2015).

\section{Psychological Support Service}

Psychological support services are well developed and considered the standard of care in paediatric HSCT settings. Psychological support is configured, therefore, as the accompaniment's relationship of an entire family system in all phases of the transplant path. The presence of psychologist with the child who undergoes HSCT:

- Enables meaningful relationships to develop

- Facilitates understanding the illness of the child in all its complexity

- Makes request for help, expressed or implied, in view of practical difficulties, organisational, relational and emotional that may arise.

The intervention must be thought according to age, and even if the parent is always present in the isolation room, one can try to find some private moments between patient and psychologist. The attention to psychological and psychopathological aspects is not realised only through specialised interventions, but it must be realised every day by all staff members. Even the nursing staff, if trained, may perform work in the role of counsellor or coach (Barrera et al. 2007).

\subsection{Transplantation Through the Ages: Teenage and Young Adults (TYA)}

\begin{abstract}
During the ages of 13-24, a person will undergoes perhaps the most rapid and formative changes of their life. The journey of transitioning from child to adult can be severely impacted when undergoing hospital treatment such as a haematopoietic stem cell transplant (HSCT) and complicates an already turbulent time. TYA patients present health professionals with a unique set of challenges, and it is important that care settings are designed to address and respond to the particular needs of young people and their families.
\end{abstract}

\subsubsection{Introduction}

A cancer diagnosis in young people is rare, with over 14000 15-24-year-olds diagnosed across Europe yearly (Stark et al. 2016). It is a growing number; the incidence of cancer in this group has increased by $50 \%$ in the past 30 years (Grinyer 2007). In response to this, guidance such as that published by the National Institute for Health and Care Excellence (NICE) aims to shape services and care to the needs of the TYA patient, which spans the ages of 13-24 years old (National Institute for Health and Clinical Excellence 2014). This is in response to research suggesting that this age group were receiving inadequate care when being treated in the paediatric or older adult setting as they have their own particular needs (Whiteson (2003). Patients undergoing HSCT require long-term clinical care beyond the acute phase of transplant and will be in regular contact with transplant clinicians and the multidisciplinary team (MDT) for a significant amount of time after bone marrow recovery and discharge from inpatient care. Care must be delivered within age-appropriate surroundings by health professionals experienced in caring for this group. 


\subsubsection{Special Indications for HSCT in TYA (AYA)}

The most common indication for HSCT in the TYA age group is in the treatment of malignant haematological diseases lymphoma and acute leukaemia (Transplant 2015). Patients with nonHodgkin's lymphoma, acute lymphoblastic leukaemia or acute myeloid leukaemia HSCT will be considered if high-risk, refractory or relapsed disease. In the case of Hodgkin's lymphoma, guidelines for teenagers indicate avoiding HSCT in the case of successful complete remission (CR) following first line of chemotherapy as chemotherapy alone usually yields successful longterm outcomes. However, once a patient requires second- or third-line treatment, the need for HSCT becomes more important (Transplant 2015). Standard recommendations are for an autologous transplant following successful CR after second-line treatment. Failure to obtain remission at this stage opens up the possibility of allograft, but this would require further discussions with local MDT. Full-intensity allografts are more routinely used in the younger adult patients as opposed to the older population as they tend to not have comorbidities associated with getting older, e.g. heart disease, and as such can tolerate stronger conditioning.

A small number of HSCTs are carried out every year for solid tumours. According to British Society for Bone Marrow Transplant (BSBMT) data, there were 162 transplants carried out on solid tumour patients of any age in 2015 within the UK, all of which were autografts (BSBMT 2015). The most common solid tumours for which HSCT is indicated includes neuroblastoma, germ cell and Ewing's sarcoma with clinicians using transplants to increase dose intensity (Gratwohl et al. 2004).

\subsubsection{Considerations for Care}

\subsubsection{Risk-Taking Behaviour and Non-compliance}

Becoming a teenager can herald a time of risktaking behaviours as adolescents push the bound- aries of their growing independence. At a time when peers are being afforded greater freedoms, often a cancer diagnosis re-establishes the dependency relationship between the young person and their family. Smoking, drinking alcohol, use of recreational drugs and engaging in unsafe sexual practices can allow the young person to regain some control, as can determining how compliant they choose to be with treatment. In the context of HSCT, indulging in unsafe behaviours can increase the risk of organ toxicity and infections. Failing to comply with supportive medications such as anti-infectives and immunosuppressives increases the morbidity and mortality rate of HSCT. As teenagers often focus on short-term outcomes if the effects of non-compliance are not immediately obvious, this can reinforce the behaviour. Similarly if there have been immediate side effects to therapy, e.g. nausea and weight gain, the patient may be less likely to adhere to medical advice. Patients who are compliant to treatment are almost three times more likely to have a better outcome than those who are not (Taddeo et al. 2008).

Gender, socio-economic status and ethnicity do not have an impact on whether a patient adheres to care (Kondryn et al. 2011). Depression and lowered self-esteem can increase rate of noncompliance, as can the perception of the illness severity. The relationship between the patient and their family can impact on how compliant a young person is with family conflict increasing the risk of non-adherence. Young patients who are treated in specialist young adult ward are more likely to be compliant compared to those who are treated in an adult cancer unit, further supporting the development of clinical areas dedicated to the care of the adolescent and young adult. This will be discussed further in the chapter.

Health professionals should be aware of the signs of non-compliance and facilitate an open and honest conversation with the patient. Confidentiality should be respected although in the instances where risky behaviour is disclosed, patients should be made aware if it is necessary to inform other members of the team. Healthy lifestyle choices should be promoted but within a 
non-judgemental environment. It is important that young patients are aware of appropriate boundaries whilst in hospital and local conduct, and operational policies must support staff in challenging risk-taking behaviours within the care environment (Smith et al. 2012).

\subsubsection{Fertility}

Fertility has been covered elsewhere in other chapters, but there are challenges unique to this age group which will be addressed in this section. Total body irradiation (TBI) and high-dose conditioning chemotherapy are highly likely to cause infertility. As often the type of transplant for the TYA patient is a full-intensity approach, this makes the risk of infertility a likely side effect of HSCT. If applicable, patients must be advised about the options of fertility preservation as part of transplant workup and given the opportunity to explore fertility preservations options although the urgency of the transplant may make this difficult.

In a study of TYA patients by Smith et al. (2007), fertility counselling was only provided to $36 \%$ undergoing treatment for cancer. Barriers to communication include a mutual awkwardness between the TYA patient and health professional when it comes to the topic of fertility. Clinicians can employ a jocular approach to young patients and find it difficult to broach sensitive topics (Quinn et al. 2009). Patients can feel confused and frightened about the potential effects of cancer treatment, or they are unable to envisage how fertility issues will impact them in the future (Smith et al. 2012).

For post-pubertal males, fertility preservation can be achieved through obtaining a sperm sample. Prior to attending fertility sessions, it should be clearly explained that the sample is obtained through masturbation, so they are prepared for the process. Sperm banking can potentially be an embarrassing process. Failing to bank a sample can leave the young person feeling disappointed and let-down, and it should be reinforced that not all attempts at sperm banking are successful.

Female fertility preservation is a more complex process. Ovarian stimulation and oocyte collection may be considered, but currently such methods have yielded limited success. Embryo collection can be difficult in this age group as they are unlikely to be ready to consider their current partners as a potential lifelong spouse (Levine and Stern 2010). Furthermore there is the added issue of time as it can take 2-4 weeks to harvest reproductive material from females. However female patients should partake in a full discussion about fertility preservation and be offered the opportunity to be referred to fertility experts as part of HSCT workup.

Discussions about fertility preservation should take place as early as possible, and parents should be included in order to support the teenager in their decision-making. Psychological input should be offered, as infertility can be one of the most impacting aspects of long-term survivorship, and there are many cultural, religious and social stigmas attached to being unable to bear a child. Although a difficult topic, in a study by Saito et al. (2005), young male patients indicated that the process of sperm banking was a positive one as they found it gave them some hope in the cancer journey, even if the sperm was never used.

\subsubsection{Impact of Treatment on the Family Unit}

Healthcare professionals looking after the TYA population must also care for the family unit and approach care holistically. During the ages of 13-24, young people undergo many developments in relation to the family unit. They may still be dependent on their parents, or they themselves may have their own children and responsibilities. Care needs to be adapted accordingly.

With TYA patients who are parents, often children will be babies and preschoolers. Moore and Rauch (2006) described what parents can expect from this age group in the context of a cancer diagnosis; even with age-appropriate explanation, under $5 \mathrm{~s}$ will have little awareness of the diagnosis and aims associated with HSCT. What they will be aware of is the absence of a parent, stress in the household and changes to their routine. Rather than understand that these are caused by illness, the child may believe that they are somehow responsible for the absence. Parents may also recognise regression in the 
child's behaviour, such as bed-wetting in previously toilet-trained children.

Parents of HSCT patients can find their relationship health with their partners placed under considerable strain. In Long and Marsland (2011) the authors noted that the needs of the parents were put on hold to prioritise the needs of the TYA patient. In the case of hospitalisation, parental separation places even further strain as there is a decrease in communication, interaction and closeness between spouses. Reaction to the treatment process varies according to gender. Males try to withhold emotion to remain strong for their families, leaving them feeling quite isolated. To their partners they can be perceived as cold and uncaring. Differences in approach can cause emotional distance and feelings of loneliness. However in some partnerships, going through the experience of having a child with cancer can make the partnership stronger, with spouses being viewed as the main source of support.

There has been limited research on the effects of HSCT on the siblings of the recipient. One of the few studies performed by Pot-Mees and Zeitlin (1987) found that siblings developed new behavioural problems during and after their brother or sister's HSCT. The respondents described feelings of post-traumatic stress disorder, anxiety and low self-esteem as their family model was perceived as 'abnormal' and 'interrupted'. Parents and health professionals should include the sibling in discussions about their brother or sister, provide them with choices and create a safe hospital environment to help them adjust to the HSCT experience (Wilkins and Woodgate 2007).

Unlike other areas of medicine, family members may be directly involved in the treatment of HSCT patients by becoming the stem cell donors and as such a second patient. Siblings are usually the first option for a stem cell source. This can create an ethical dilemma for parents and healthcare staff, especially if the potential donor is a minor. What if the child refuses? What are the limitations of parental decision? What are the consequences for the child who refuses to donate? The Human Tissue Authority provides guidance on consenting a minor for stem cell collection in their 2015 guidelines (Human Tissue Authority 2015 ).

There is a significant potential for psychological impact on those siblings who undergo HLA tissue typing, regardless of whether they actually turn out to be a match or not. In MacLeod et al. (2003) siblings reported feeling as if they had 'no choice' about being tested and donating if matched. Reluctance was often not because they did not want to help but rather the fear of the procedure. In the case of siblings who were not matched, they described feelings of relief but also guilt. If they were matched but the sibling died, donors felt angry and blamed themselves, especially in the context of graft failure or graftversus-host disease. By comparison, siblings in Wiener et al. (2008) found that the process of donating harboured an increase closeness between themselves and their siblings and their parents. Being able to help gave them a sense of pride. Response to the process does seem to be linked to whether the transplant was successful or not. A further family stem cell source is the parent. In the case of failing to find a suitable donor through siblings or the register, often parents will make a motivated stem cell donor. However, as in the case of the sibling, parents can also be left with profound feelings of guilt if the transplant fails (Barfield and Kodish 2006).

Health professionals have a duty to care for the family as a unit. Through the use of multidisciplinary team meetings, staff should be aware of family dynamics. Healthcare professionals should guide patients and their families on appropriate open communication though needs will vary depending on the family. For patients who are parents of young children, they should reassure the child that mum or dad's absence is not their fault and that they have done nothing wrong. Donors, whether siblings or parents, should be involved in the HSCT process from the start, and the complex variables associated with transplant success be carefully explored. Members of the MDT, such as psychologists, youth support workers, school teachers, social workers etc. should be involved early in the journey with patient con- 
sent. Creating a family-friendly space in the clinical environment can encourage children and siblings to visit. Key workers should be aware of support networks and resources locally to refer or signpost as appropriate.

\section{Case Study}

A 14-year-old girl was treated in a TYA unit for acute lymphoblastic leukaemia. From an early point in treatment, it was clear that disease was high risk due to existing cytogenetics and poor response at reassessment. She was placed on UKALL 2011 Regimen $\mathrm{C}$ but experienced complications including methotrexate encephalopathy and drug reactions to asparaginase and the alternative, erwinase. Treatment was suboptimal. The clinical team decided to test her brother and sister to plan for a sibling allograft when a repeat bone marrow showed a significant amount of minimal residual disease after 6 months of treatment. Her sister was found to be a $10 / 10$ HLA match. However her mother struggled greatly with the fact that her 'healthy' child would be put through procedures, especially as she was only 10 years old. The younger child was clear on her intention to help her sister but did experience distress when subjected to blood tests. This exacerbated the inner turmoil felt by her mother as she worried about the eventual bone marrow harvest and openly discussed refusing consent for the procedure in front of her 14-year-old daughter, despite knowing that finding an alternative stem cell source was unlikely as the patient was from a complex ethnic background. With the help of the available psychological team and activity coordinators at the paediatric and TYA centre the patient, her sibling, mother and family received separate counselling, and the resulting harvest was successful.

\subsubsection{Body Image}

Side effects of drugs used in the HSCT process can cause significant physical changes to a patient's appearance. This is not exclusive to the TYA patient but can be more psychologically harmful as they are at an age where physical appearance is central to their world and when feeling different from peers can have a negative impact on self-esteem (Smith et al. 2012). Issues such as weight gain and alopecia can have a psychological impact which is greater compared to the older adults. Appearance concerns amongst TYA cancer patients have been linked to lower self-esteem, depression, anxiety, feelings of loneliness and suicidality and decreased treatment compliance (Fan and Eiser 2009).

Weight loss is an inevitable part of the acute and recovery phase of HSCT as patients struggle with the gastrointestinal side effects of treatment. For female patients, weight loss can alarmingly seem like a positive aspect of treatment in line with societies' perceptions of what is attractive. The opposite is true of male patients. It is becoming more normal for young males to try to obtain a muscular physic through careful gym and diet regimens. Often newly diagnosed young males are bulky with little body fat. Anecdotally the biggest struggle they tend to have is with muscle wasting aspect of HSCT, in the context of fatigue, poor appetite and reduced exercise tolerance. Research into this area with the TYA population is limited although a study by Rodgers et al. (2010) interviewed TYA patients on their experiences of nutrition post-HSCT. Participants described abnormal appetites until day 50 postHSCT, by which point they were able to manage a small amount of food. Progress continued, with stark improvement in feeling hungry by day +100 . Participants were able to correlate the link between improved eating habits and appetite with returning to their 'normal selves', advising future patients to have some control over what they eat and portion size rather than being forced into eating by parents and health professionals.

Weight and hair gain is something that not everyone associates with chemotherapy. Often media depictions of cancer patients include 
gaunt, cachexic figures with alopecia. For patients receiving high-dose steroids, for example, in the treatment of graft-versus-host disease, a typical side effect includes development of facial swelling, known as 'moon face' and unwanted facial hair. This can drastically alter appearance and be devastating for a young person. This can also lead them to become non-compliant to the treatment with poor consequences for their treatment success.

Alopecia is a common and well-known side effect of chemotherapy and usually one of the first things TYA patients ask about when discussing treatment. Hair is often very much tied into identity, and the idea of losing it can make some teenagers refuse treatment when the idea is initially discussed. Youth support workers and nurse specialists are excellent at helping to organise a replacement before hair loss starts to occur (usually 2 weeks after the start of chemotherapy). There are wigs made of real hair which can often be difficult to identify next to the real thing. However a lot of hair replacement focuses on females, with male patients finding options to be limited.

Conditioning regimens containing TBI can impact on the growth of patients who are treated at a young age, i.e. prepubertal (Leiper 1995). This is due to the radiation administered to the hypothalamic-pituitary axis and the resting reduction to the growth hormone. Replacement therapy can aid to reduce further loss of height, but cannot reverse loss. Clinicians need to carefully monitor growth of patients to ensure early intervention (Lowis 2000).

\subsubsection{Impact on Life}

Approximately $60 \%$ of children and adolescents who are long-term survivors of HSCT experience late effects, both of the physical and psychological nature (Forinder and Posse 2008). Fertility and growth issues have been covered already in this chapter, and organ toxicity associated with HSCT is written about in other sections of this book. There are other ways that HSCT impacts of life which are unique challenges to the TYA patient.

For the adolescent and young adult, peers are an important feature of life. However patients of this age undergoing a HSCT experience social isolation from their friends and community. This is not only due to physical absence from school, university and work but also a difficulty on the part of the healthy young person to understand and empathise with the experiences of their unwell friend (Thomas et al. 2006). From the perspective of the survivor of a HSCT, they can find it difficult to relate to their peers after what they have been through. In interviews with Forinder and Posse (2008), TYA HSCT patients felt they had a different perspective on life, with material things and physical appearance not being as important as they once were. That said, subjects were conscious of their change in appearance and upset at looking different to those in their social network.

The relationship between the parents and the unwell adolescent is difficult to navigate. Necessary increased dependency is at odds with the need for autonomy that is typical at this age. This can lead to direct conflict between the two parties, especially once the TYA patient has completed the acute phase of the transplant. A sharp difference of priorities can exist between parent and patient (Grinyer 2009). Research also suggests that TYA patients may not have fully developed executive function due to regression and cognitive development delay which adds to the tension between the parent and patient relationship (Kaufman 2006).

Survivorship is a growing area of research as outcomes from cancer treatment improves. Health professionals and researchers recognise that completion of cancer treatment is the start of a difficult journey of adjustment and transition. Clinical staff need to consider the fall out of treatment, and patients should be aware that they can and should continue to access support. Treatment within dedicated TYA clinical areas can help patients to access peer support which is tailored more to their development needs.

\subsubsection{Teenager as a Child vs. Adult}

Under 18s present legal challenges for healthcare professionals as the young person must be assessed 
on their ability to make appropriate decisions about their care on an individual basis. In the following section, issues of consent, confidentiality and guardian roles are discussed. Much of this part will discuss current legislation within the UK. Health professionals should refer to local legislation for further clarity.

\subsubsection{Consenting for Treatment}

Informed consent is a cornerstone of medical practice. Violation of this has legal implications for clinicians but more importantly jeopardises the ethical rights of the patient (Bayer et al. 2011). In order to satisfy the principles of informed consent, it must be given freely and with full comprehension. Patients must be provided with adequate information in understandable terms. Treatment options should be reviewed, and a discussion about the risks, benefits and alternatives to the proposed treatment should take place and be documented. Signing of a consent form is symbolic, representing completion of the consenting process.

Informed consent is a relatively straightforward process when concerning over $18 \mathrm{~s}$ as long as the individual has capacity. In the UK, patients between 16 and 18 can consent for treatment but may not be able to refuse treatment in the case of saving their lives or preventing serious harm. Under 16 s may legally consent if they meet certain criteria of being Gillick competent. This principle is based on a case in the 1980s where Victoria Gillick took her local authority to court to prevent them from providing contraception to her children without her knowledge (Wheeler 2006). The high court determined that minors under 16 have the potential to independently consent to treatment if deemed competent to do so. However it is a good practice to involve the young person's family in the process. In the case of under 18s who are deemed Gillick competent but refusing treatment, it is possible for the decision to be overturned where it will lead to death or serious injury (Department of Health 2009).

In the case where a minor cannot independently consent and parental involvement is required, the Oviedo Convention recommends the use of the term 'authorisation' rather than 'consenting on behalf of a child' as the former relates to the concept of a third authority, i.e. the parent, and is slightly different from informed consent. As informed consent is an expression of personal choice, it can only relate to the person being treated. Authorising treatment is acknowledging that it is in the best interests of the child. Furthermore the Oviedo Convention requires that the opinion of the minor must still be taken into consideration. Thus the decision-making process involves three parties: the clinicians, the person with parental responsibility and the child undergoing treatment (Nicolussi 2015). According to the Children Act 2004, parental responsibility extends to the child's parents if married at the time of conception or birth, the child's father if not married to the mother but who features on the birth certificate or the child's legally appointed guardian or a local authority who has been granted a care order in respect of the child.

Scenarios where there are disputes between parties involved in treatment decisions are rare but do occur. This can be between patients and their parents, between health professionals and the family or between parents to provide more common instances. A well-known example is when parents who are Jehovah's Witnesses refuse blood transfusions on behalf of their child. Cultural beliefs should be respected, but bone marrow failure can be a life-threatening complication of HSCT. In instances such as this, which can be pre-empted, plans should be made about how to deal with the complication before it arises, i.e. the use of erythropoietin as an alternative. Unfortunately not every eventuality can be considered, and advice may need to be sought through legal channels which will provide protection to the patient, family and the health professionals concerned.

\subsubsection{Communication}

Regardless of whether a minor is able to consent, they should still be encouraged to participate in discussions about their care, and if they choose to attend consultations, information should be directed at them. Healthcare professionals should give the same time and respect to young people as they would do to adult patients. Information 
should be provided using language that is understandable, giving all involved parties the opportunity to ask questions. Discussions should be truthful and open, with consideration given to confidentiality. The information provided should be appropriate to the age of the young person and include a discussion about:

- Their illness and proposed treatment

- The purpose of investigations and treatments and what they involve

- Benefits and risks, including of not having treatment

- Who will be responsible for their care

- Their right to ask for a second opinion or retract consent if deemed capable (GMC 2007)

If is justifiable to keep the above information from the young person if you think that it will cause them serious harm (this does not include concerns about upsetting them) or if the patient asks you not to tell them, preferring to leave someone else to make the decision for them.

Often guardians and young people can struggle to have honest discussions together as they are afraid of upsetting each other especially in the context of sensitive subjects. It should be made clear to the young person that they can have consultations on their own. A chaperone may be appropriate, although this could deter the young person from having a frank discussion.

\subsubsection{Confidentiality}

Respecting confidentiality is important in harbouring good relations with young people, making them feel confident about seeking care and advice. If required to share information with parents or other health professionals, the young person should be made aware and agree. If they refuse, there are still circumstances where information should be disclosed including where it would be in the public's best interest, when it is in the best interests of the young person when they lack capacity and when disclosure is required by law. Examples include if the information would help prevent or prosecute in the case of a serious crime (usually against the young person) and if the patient is engaging in activities that might put them at risk, e.g. serious addiction and self-harming.

\subsubsection{TYA Cancer Care in Europe: A General Review}

Across Europe, cancer is the second cause of death amongst 15-24-year-olds (Gatta et al. 2009). Despite this, the services for this population remain in the developing stage in comparison to that of children or older adults. This is a strive for change, and an example of this is the European Network for Cancer Research in Children and Adolescents (ENCCA) programme which aims to share knowledge and services across the continent. Stark et al. (2016) summarised the work across individual countries and set out guidelines with collaborative aims to:

- Not necessarily have agreed age cut-offs set across Europe; rather treat according to the needs of their population.

- Provide an age-appropriate environment for TYA patients to complete their care, with services tailored to the needs of the patient and family.

- Have an active relationship between paediatric and adult oncologists or a dedicated TYA team, including specialist health professionals such as nurses, social workers, psychologists, teachers and activity coordinators.

- Have a fertility preservation programme.

- Have a transition programme for those moving from child to TYA services and TYA to older adult care.

- Have clinical trials available to the TYA population in varying tumour groups.

Stark et al. (2016) also summarised progress of individual countries in regard to TYA care:

The UK pioneered the TYA model back in the 1990s through collaboration between the Teenage Cancer Trust (TCT) and National Health Service (NHS). As such the pathway swell is defined. All TYA patients with a cancer diagnosis must be discussed at a TYA MDT, and those between 13 
and 19 must be treated in a dedicated TYA centre. The service undergoes yearly peer review, and lead clinicians are at the forefront of specialist networks. There is a separate TYA clinical studies group with the aim of including the availability of trials to this patient group. TYA health professionals have their own UK professional membership organisation which provides peer support and sharing of information between services. There are 25 TYA centres across the county, and development of such services is discussed in detail in the next section.

In Germany there is separate infrastructure for paediatric and adult cancer patients with a strict age barrier of 18 years separating them. The majority of adolescent care is performed within paediatric oncology. However practice is changing and a collaborative approach is happening, with some centres creating TYA-specific MDT programmes.

In Italy the Committee on Adolescents was formed by the Associazione Italiana Ematologia Oncologia Pediatrica in 2010 to ensure TYA cancer patients have prompt, adequate and fair access to the best care. Since then two TYA units have been opened. A national task force dedicated to teenagers and young adults with cancer was set up in 2013 to push the agenda for TYA care further.

In France research by Desandes et al. (2012) showed that $82 \%$ of $15-18$-year-olds with cancer were treated in an adult environment and few were enrolling clinical trials. This prompted the initiation of an improvement plan. Since then eight TYA units and three specialist centres have been opened with dedicated teams; improvements have been made to the inclusion of TYA patients in clinical trial, and a specific psychosocial programme has been initiated. The Institut de France planned to create localised care pathways and has started a national association to focus on cancer care for patients between 15 and 25 years old.

In Spain in 2011 the Adolescents with Cancer Committee was set up by the Spanish Society of Paediatric Haematology; however, a survey in 2014 showed that over 14-year-olds were still generally being treated in adult care settings
(Lassaletta et al. 2013). TYA oncologists and patients have founded the charity 'Spanish Association of Adolescents and Young Adults with Cancer' to create support for young people with cancer and push the TYA agenda.

In Denmark a TYA project started by nurses commenced in 2000 at Aarhus University. A national initiative is also being planned to bring together the collective view of young patients, to create TYA-focused unit and to specialise treatment.

In 2013 in the Netherland health professionals started a national TYA project dedicated to the care of 18-35-year-olds and focused on quality of life, late effects and fertility.

In Portugal that is no national project yet, but in Lisbon a project has commenced to create a TYA unit for patients aged between 16 and 25. In other countries, e.g. Belgium, Bulgaria, Czech Republic, Ireland, Greece, Hungary, Lithuania, Norway, Poland, Romania, Slovenia and Sweden, there is no national project yet, but there are some local projects occurring.

\subsubsection{Development of TYA Cancer Units:The UK Experience}

It was first recognised that young UK patients had specific needs in the 1950s with the publication of the Platt Report (Ministry of Health 1959 ). Publication of the Calman-Hine report in 1995 particularly acknowledged the issues faced by young cancer patients. Treating 13-18-year-olds in the same units as toddlers or over $18 \mathrm{~s}$ with the elderly fails to provide care that meets their needs. The UK has been at the forefront of developing TYA-specific treatment areas; however, age-appropriate care is still not available to all.

The Teenage Cancer Trust charity was set up over 10 years ago to act as support and advocate for young people facing cancer. Alongside other charity organisations internationally including CanTeen Australia, CanTeen New Zealand, LIVESTRONG and SeventyK, they created the International Charter of Rights for Young People with Cancer which states that young people with cancer should: 
- Receive education about cancer and its prevention

- Be taken seriously when seeking medical attention to ensure that they receive the earliest possible diagnosis and referral for a suspected cancer

- Have access to suitable qualified health professionals with significant experience in treating patients with cancer in this age group

- Access to suitable clinical trials

- Receive age-appropriate support

- Empowered in making decisions

- Fertility preservation

- Access to specialised treatment and services in age-appropriate facilities

- Financial support

- Long-term survivorship support

The Teenage Cancer Trust was set up over a decade ago and works in partnership with the National Health Service to open inpatient and outpatient cancer units, providing education, specialist staff and annual meetings to raise awareness of the issues associated with caring for this age group. In 1990 they opened the first dedicated unit at the Middlesex Hospital in London and currently have 28 units operating across the UK. Other European countries have followed with the Institut Gustave-Roussy in Paris opening in 2003 (Whelan 2003). Development of TYAdedicated units is down predominantly to initiatives in response to local needs rather than a general coordinated health policy. As a consequence there is great variation in the provision of services for TYA patients with cancer across the UK. In 2005 the National Institute for Health and Care Excellence (NICE) published recommendations for health professionals treating teenager and young adults with cancer. Amongst the guideline was advice about where young people should be treated; under $18 \mathrm{~s}$ should be treated in a principle treatments centre, and those 19 and over should be offered a choice about where they go. Principle treatment centres are designed to offer expert medical care, an age-appropriate environment, psychosocial support and access to a multidisciplinary team.
During the development stage of a new unit, often patients will be asked for their opinion and input into the facilities and design. Use of the internet is important in this age group as a means of staying in touch with normality whilst an inpatient, so facilities should be provided. Patients should have access to appropriate equipment including game consoles, music, pool tables etc. Designated recreational areas can provide a space for patients to socialise and relax away from their hospital beds. This can also encourage peer support as patients interact in communal spaces. Support for the young person can be gained by having somebody staying with them, and clinical areas should be able to accommodate. This is often possible in paediatric and teenage settings but can be difficult to provide in adult units.

The ethos of TYA care is to approach holistically. This is achieved by presenting each new patient at weekly TYA and site-specific MDTs. During TYA MDTs, health professionals from across the service attend to participate in discussions about new patients and their planned treatments. All TYA patients, irrespective of place of treatment, should be discussed at a TYA MDT to ensure that they have the opportunity to receive the correct support. According to (Smith et al. 2012) barriers to setting up a TYA MDTs, including time constraints, perceived duplication and resources. However uses of MDTs are thought to improve clinical trial recruitment, outcomes and multi-agency working.

Due to duration of follow-up post-HSCT, patients may be required to transition as they pass landmark birthdays. This should be a planned process that addresses the needs of TYA patients with chronic health problems as they move from child-centred care to the TYA setting or TYA care to the adult health system. This can be a difficult time for patients and their families as they leave behind the team that has moved them through the acute phase of the HSCT process and with whom they have built up a strong bond. Planning may take a number of months and should be approached sensitively. The process can be helped by patients visiting the new units and good communication between all parties. 


\subsubsection{Summary}

- TYA cancer patients include those aged between 13 and 24 years old.

- Often HSCT indications in this age group are for malignancies including refractory or relapsed leukaemia and lymphoma.

- There are unique challenges facing this age group when diagnosed and undergoing treatment.

- One significant challenge is the impact that a cancer diagnosis has on the family unit especially in the younger siblings providing the stem cell.

- Even when considered a minor, patients do still need to be assessed for competence and afforded the same respect as adult patients.

- Partnership between the NHS and charities such as the Teenage Cancer Trust can provide an age-appropriate environment for patients and their families.

- There is still much work to be done across Europe to ensure each patient is getting care that is responsive to their needs.

\subsection{Transplanting the Adult and the Older Adult: Nursing Considerations}

\footnotetext{
Abstract Older people are usually identified by their chronological age, and persons aged 65 years or over are often referred to as 'elderly' (WHO 2010). The median age at diagnosis of patients with acute myeloid leukaemia (AML), myelodysplastic syndromes (MDS), chronic lymphatic leukaemia (CLL), multiple myeloma (MM) and non-Hodgkin's lymphoma (NHL) is over 65 years old (Eichhorst et al. 2011; NCI 20003; Palumbo and Anderson 2011; Sekeres 2010; Smith et al. 2011; Siegel et al. 2015). Most of these haematological diseases are not curable unless an allogeneic or autologous haematopoietic cell transplantation can be performed.

Currently the indications for and subsequently the use of haematopoietic cell transplantation as a treatment option in older adults with haemato-
}

logical malignancies are increasing, yet the majority of our experience is with patients under the age of 65 .

Older patients however represent a very heterogeneous group with respect to overall health status; some individuals stay fit, whilst others are frail or become fragile suddenly.

In order to help healthcare professionals decide on the best treatment option for their older patients, geriatric assessment (GA) (Extermann et al. 2005) can identify unknown medical, functional, cognitive and social issues, making it possible to plan early interventions. Although GA still requires prospective validation in larger cohorts, this assessment is able to predict survival and toxicities and to detect unknown geriatric problems.

A substantial percentage of older adults have more difficulties processing and remembering information than younger ones. It is important to make sure that also older adults understand their disease, the prognosis and the treatment plan to make an informed decision. Therefore, it is essential to assess cognitive functioning and in case of mild cognitive impairment that the information is tailored to reflect the individual's needs.

Most healthcare professionals working in haematology settings are not trained in geriatrics. The aim of this section is to describe GA, to provide information about the increasing prevalence of certain risk factors (impaired cognitive function, medication non-adherence) and how patient information can be adjusted to the needs of older patients.

Keywords Older patients - Fragile • Geriatric problems - Geriatric assessment • Patient information

\subsubsection{Differences Between Older and Younger Patients}

The incidence of acute myeloid leukaemia (AML), myelodysplastic syndromes (MDS), chronic lymphatic leukaemia (CLL), multiple myeloma (MM) and non-Hodgkin's lymphoma 
(NHL) increases with age, with the majority of patients being over 65 years of age (Eichhorst et al. 2011; NCI 20003, Palumbo and Anderson 2011; Sekeres 2010; Smith et al. 2011; Siegel et al. 2015 ). Most of these haematological diseases are not curable unless the appropriate allogeneic and/or autologous haematopoietic cell transplantation is performed.

Chronological age is becoming less of a barrier to reduced-intensity conditioning in allogeneic haematopoietic cell transplantation (HCT), and as a result, HCT in the older adult population is increasing. However the majority of experience with stem cell transplantation remains amongst younger adults.

\section{Older age is still associated with:}

- Pharmacokinetic and pharmacodynamic changes

- An increased risk of toxicities and infectious complications from chemotherapeutic agents

- An impaired immune system

- A high prevalence of comorbid conditions and an overall worse performance status

These factors may result in higher risks of non-relapse death after both autologous and allogeneic HCT (Artz and Chow, 2016; Mamdani et al. 2016).

Older patients represent a very heterogeneous group in terms of health and functioning; as whilst some individuals remain fit, others are frail or become fragile suddenly.

More than half of adults aged over 65 have three or more medical problems (Boyd et al. 2012) and may be taking multiple medications, making care more complex.

In older patients, therapeutic decisions are widely based on the patient's age, general health, the disease features, as well as the patient's personal wishes, and clinical judgement. However, even amongst older patients with a good performance status, geriatric impairments are reported (Extermann et al. 2005). In order to help healthcare professionals (HCP) work with patients and caregivers to decide on the best treatment option, GA can be used to objectively evaluate patients, identifying medical, functional, cognitive and social issues, making it possible to uncover potential problem areas and plan early interventions. Although GA still requires prospective validation in larger cohorts, and in the transplant setting (Elsawy and Sorror 2016), this assessment is able to predict survival and toxicities (Artz et al. 2006; Palumbo et al. 2015) and to detect unknown geriatric problems, making it possible to plan early interventions and to influence treatment decisions (Kenis et al. 2013).

\subsubsection{Geriatric Assessment}

GA strategies need to be implemented early on in the patient pathway in order to facilitate decisionmaking in relation to the optimal approach to treatment. It can assist in identifying patients most likely to benefit from standard induction and post-remission therapies, as well as in the consideration of performing a HCT. To determine the best treatment for the patient, GA is needed to systematically uncover medical, functional, cognitive and social issues, which may compromise the treatment. Table 8.2 provides an overview of domains and tools commonly used. Domains are assessed by means of commonly used tools to measure functional status, cognitive function, nutritional status, comorbidities, polypharmacy and socio-economic status. Some use this in combination with a short screening tool to detect vulnerability. An appropriately trained healthcare professional can perform the assessment, and in some cases this may be a nurse. GA instruments aid in identifying potential problems; however, when the problem is identified as being severe, a thorough assessment is needed to understand the cause. In order to optimise the outcomes of the older patient, a geriatric intervention or referral may be necessary, for example, to the geriatrician, dietician, physiotherapist, social worker or psychologist.

A full GA can be time-consuming and burdensome for HCP who are not trained in the evaluation of older adults. The use of more simplified screening tools like the Vulnerable Elders Survey (VES) (Saliba et al. 2001) and G8 screening tool (Soubeyran et al. 2011) (see Table 8.2) can be 
Table 8.2 Comprehensive geriatric assessment domains and commonly used tools, and screening tools

\begin{tabular}{|c|c|c|}
\hline Domain & Tools & Reference \\
\hline \multirow[t]{4}{*}{ Functional status } & Performance Status (PS) & $\begin{array}{l}\text { Karnofsky and Burchenal (1949), } \\
\text { and Mor et al. (1984) }\end{array}$ \\
\hline & Activities of Daily Living (ADL) & Mahoney and Barthel (1965) \\
\hline & Instrumental Activities of daily Living (IADL) & Graf (2008) \\
\hline & Self-reported number of falls & Peeters et al. (2010) \\
\hline Comorbidities & $\begin{array}{l}\text { hematopoietic cell transplantation comorbidity } \\
\text { index (HCT-CI) }\end{array}$ & Sorror et al. (2005) \\
\hline Polypharmacy & comprehensive drug review & \\
\hline \multirow[t]{2}{*}{ Geriatric syndromes } & Mini mental State Examination (MMSE) & Folstein et al. (1975) \\
\hline & Geriatric Depression Scale (GDS-15) & Almeida and Almeida (1999) \\
\hline \multirow[t]{3}{*}{ Nutrional status } & Malnutrition Universal Screening Tool (MUST) & Stratton et al. (2004) \\
\hline & $\begin{array}{l}\text { Simplified Nutritional Assessment Questionnaire } \\
\text { (SNAQ) }\end{array}$ & Kruizenga et al. (2005) \\
\hline & Mini Nutrional Assessment Short Form (MNA) & Guigoz (2006) \\
\hline \multicolumn{3}{|l|}{ Screening tool } \\
\hline \multirow[t]{4}{*}{ Vulnerable elders survey } & Age & Saliba et al. (2001) \\
\hline & Self-rated health & \\
\hline & 6 physical function limitations & \\
\hline & 5 IADL/ADL items & \\
\hline \multirow[t]{6}{*}{ G8 Screening tool } & Appetite, Weight loss, BMI & Soubeyran et al. (2011) \\
\hline & Mobility & \\
\hline & Mood and cognition & \\
\hline & Number medications & \\
\hline & Patient-related health & \\
\hline & Age categories & \\
\hline
\end{tabular}

employed in an initial appraisal, identifying those who would benefit most from a more detailed and complete GA.

\subsubsection{Functional Status}

An important determinant of frailty is functional status, including Karnofsky's performance status (PS) (Karnofsky and Burchenal 1949; Mor et al. 1984), the activities of daily living (ADL) (Mahoney and Barthel 1965) and the instrumental activities of daily living (IADL) (Graf 2008). The PS is utilised routinely in HCT and is a global estimate of the overall health of patients according to their doctor. The ADL measures the level of independence or dependence of patients and, in terms of limitations to self-care, mobility and being able to walk and continence status.

The IADL describes the more complex ADLs necessary for living in the community and assesses the competence in skills such as shop- ping, cooking and managing finances, which are required for independent living.

Evaluation of gait difficulty and self-reported number of falls may also be useful when looking at functional status. Problems may be caused by fatigue, muscle weakness, dizziness or neuropathies induced by cancer or its treatment and can cause significant mortality and morbidity.

\subsubsection{Vision and Hearing Impairments}

Many older adults have either a visual impairment, a hearing impairment, or both. There is evidence of an association between hearing impairment and cognitive decline amongst older adults (Valentijn et al. 2005). An evaluation of visual and hearing acuity of any patient should be undertaken during the physical assessment. Where possible, hearing and visual impairments should be corrected, so that elders can function better, promoting greater independence. 


\subsubsection{Comorbidity and Polypharmacy}

Typical older adults have multiple comorbidities. For HCT, comorbidity can be assessed by using the haematopoietic cell transplantation comorbidity index (HCT-CI) introduced by Sorror et al. in 2005, as an evaluation of organ dysfunction for potential HCT recipients. The HCT-CI was developed from the historical Charlson comorbidity index (Charlson et al. 1987).

Due to existing comorbidities, the older patient is often taking multiple medications each with their own side effects, interactions and contraindications. Polypharmacy, (defined as an excessive number of medication $(\geq 5)$ ), is sometimes further increased by medications which can be bought over the counter without prescription. Some of these medications may interact with prescribed cancer treatments or even supportive medications such as immunosuppressive agents that are used following HCT. A comprehensive drug review is strongly advised before initiating therapy and then regularly throughout the patients' treatment pathway to maintain accurate records of concomitant drugs and ensure avoidance of potentially inappropriate medications.

\subsubsection{Cognitive Functioning}

Although cognitive decline is acknowledged to increase with age, significant variability is noted amongst the older population (Greene and Adelman 2003). They define mild cognitive impairment as 'deficits in memory that do not impact on daily functioning'.

However, consequences of even mild cognitive impairment are significant because these patients may have more difficulty understanding the risks and benefits of treatment and also adhering to complex cancer treatment regimens. It should be remembered that a diagnosis of cognitive impairment does not necessarily mean that the patient is incapable of making decisions and consenting. Most patients are still able to understand the risks and benefits of treatment and of being involved in research. It is important that researchers do not automatically exclude patients with cognitive impairment from treatment but that every effort is made to ensure that patients are fully informed in order to be able to give their consent.
Assessment of cognitive function is included as a domain in GA. In addition, the Mini-Mental State Examination (MMSE) is widely used as a screener for cognitive impairment and for dementia in older persons (Folstein et al. 1975) .

\subsubsection{Geriatric Syndromes}

Geriatric syndromes include dementia, depression, delirium, osteoporosis, falls and fatigue. Specific geriatric syndromes can be assessed with instruments such as the MMSE and the geriatric depression scale (GDS-15) (Almeida and Almeida 1999). The MMSE assesses to which degree the person is alert, oriented and able to concentrate and perform complex mental tasks and affective functions and detects signs of dementia (Folstein et al. 1975; Sattar et al. 2014). The geriatric depression scale (GDS-15) searches for signs of depression (Sheikh and Yesavage 1986; Almeida and Almeida 1999). The presence of dementia and/or depression is associated with a negative impact on survival (Pallis et al. 2010).

\subsubsection{Medication Adherence}

During HCT it is imperative that patients adhere to the prescribed treatment. Non-adherence leads to poorer health outcomes, such as increased incidence of transplant-related morbidity and mortality, higher cancer recurrence rates and shorter survival (Puts et al. 2014).

Older age has not been identified as a risk factor for non-adherence, unless the older adult himself perceives insufficient social support. For older adults, certain factors are known to impact upon medication non-adherence. These include factors relating to the healthcare system and the treatment team:

- High cost of medication whilst patient income is low

- Incomplete insurance coverage

- Lack of coordinated care

- Individual factors such as misunderstanding of instructions, intentional choice of medication and non-adherence to accommodate the individuals' lifestyle and daily activities (Van Cleave et al. 2016) 
Whilst there is no screening tool currently available for non-adherence in gero-oncological patients, there are several existing medication adherence scales available to assess patients' adherence to medication (Lam and Fresco 2015).

\subsubsection{Nutritional Status}

Nutritional deficiency and malnutrition are common in older adults. The presence of weight loss and/or anorexia points towards malnutrition, which increases vulnerability to illness. In order to determine nutritional status, screening instruments like the Malnutrition Universal Screening Tool (MUST) (Stratton et al. 2004) or Simplified Nutritional Assessment Questionnaire (SNAQ) (Kruizenga et al. 2005) are available. In all these screening instruments, unintentional weight loss in a short time is a fixed-item parameter to evaluate malnutrition. In order to diagnose malnutrition, the Mini Nutritional Assessment (MNA) (Guigoz 2006) can be used. The MNA assesses:

- Decline in food intake

- Weight loss, mobility

- Neuropsychological problems

- Body mass index

- Number of medications taken per day

- Patients' assessment of their health status compared with others their own age

A multidisciplinary approach to nutrition assessment, care planning, intervention and evaluation in HCT patients should be advocated where possible, with the involvement of healthcare professionals such as dieticians and nutrition specialist teams in collaboration with the medical and nursing team.

\subsubsection{Socio-economic}

Social support, persons' general living conditions as well as availability and adequacy of caregivers should be an integral part of GA. There are different types of support, such as:

- Everyday emotional support

- Emotional support with problems

- Appreciation support

- Practical support
- Social companionship

- Informative support

Everyone needs everyday support in a certain way. The type and amount of support needed will depend on the individual and also the phase of the illness and treatment. Consideration should also be given to the well-being of the caregiver as the quality of life and quality of care of the patient also depend upon this factor.

\subsubsection{Decision-Making}

Older persons may have grown up in a healthcare culture where decision-making was more paternalistic. As a result, this may either lead to lower requests for information by the patient or to a risk of poor overall communication. For most young patients, the decision and desire to be transplanted are often clear. For older patients however, the decision is often far less obvious, and the choice to proceed to HCT is a complex one (Randall et al. 2016). Patients might think they are 'too old' for HCT or be concerned whether they can find an available caregiver and whether they have enough money for extra costs incurred or that it will impair their quality of life (Randall et al. 2016). Medical information about the general process and outcomes of the transplant, donor sources, medications, timelines, and risks and benefits of the procedure are usually provided after induction therapy has been successful. However, older people have more difficulties processing and remembering information than younger ones (Posma et al. 2009), and cognition may have been affected further by the chemotherapy that has been given (Williams et al. 2016). It is important, therefore, to provide education about HCT, which is gradual and repeated during induction and, afterwards, presented using plain language, empowering the older patient to make the decision about transplant (Randall et al. 2016). In order to improve the patients' ability to actively participate in the decision-making process and increase treatment adherence, a step-by-step approach should be considered (Posma et al. 2009) and narrowed down to what is meaningful to make a decision (D'Souza 
et al. 2015, Posma et al. 2009). Regarding risks and general knowledge of medical procedures, written information, multimedia interventions, extended discussions and test/feedback techniques can improve the patients' understanding (Schenker et al. 2011). Particular attention should be paid to implementing interventions that are accessible to patients with limited literacy and/or limited vision. These groups are at increased risk for poor comprehension.

\section{References}

\section{Transplanting the Child}

Asadi M, Manookian A, Nasrabadi AN. Parent' experiences of their children bone marrow transplantation: a qualitative study. Int J Hema Oncol Stemm Cell Res (IJOSCR). 2011;

Badon P, Cesaro S. Assistenza infermieristica in pediatria. In: CEA, editor. 2nd ed. CEA; 2015

Barrera M, Andrews GS, Burners D, Atenafu E. Age differences in perceived social support by paediatric haematopoietic progenitor cell transplant patients: a longitudinal study. Child Care Health Dev. 2007;34(1):19-24

Bauk K, Andrews A. The pediatric sibling donor experience in hematopoietic stem cell transplant: an integrative review of the literature. J Pediatr Nurs. 2013;28:235-42.

Bingen K, Kent MW, Rodday AM, Ratichek SJ, Kupst MJ, Parsons SK. Children's coping with hematopoietic stem cell transplant stressors: results from the journeys to recovery study. J Child Health Care. 2012;41(2):145-61.

Chang G, Recklitis SJ, Recklitis C, Syrjala K, Patel SK, Harris L, Rodday AM, Tighiouart H, Parsons SK. Children's psychological distress during pediatric HSCT: parent and child perspectives. Pediatr Blood Cancer. 2012;58:289-96.

Committee on Bioethics Children as Hematopoietic Stem Cell Donors. Pediatrics. 2010;125:392; originally published online 25 Jan 2010.

Manookian A, Nikbakht Nasrabadi A, Asadi M. Children's lived experiences of hematopoietic stem cell transplantation. Nurs Health Sci. 2014;16:314-20.

Munzenberger N, Fortanier C, Macquart-Moulin G, Faucher C, Novakovitch G, Maraninchi D, et al. Psychosocial aspects of haematopoietic stem cell donation for allogeneic transplantation: how family donors cope with this experience. Psychooncology. 1999;8(1):55-63.

Mona M. 2015 link: http://nursingexercise.com/ child-growth-development-overview.
Norberg L, Mellgren K, Winiarksi J, Forinder U. Relationship between problems related to child late effects and parent burnout after pediatric hematopoietic stem cell transplantation. Pediatr Transplant. 2014;18:302-9.

Packman W, Weber S, Wallace J, Bugescu N. Psychological effects of hematopoietic SCT on pediatric patients, siblings and parents: a review. Bone Marrow Transplant. 2010;45:1134-46.

Passweg JR, Baldomero H, Peters C, Gaspar HB, Cesaro S, Dreger P, Duarte RF, Falkenburg JHF, FargeBancel D, Gennery A, Halter J, Kröger N, Lanza F, Marsh J, Mohty M, Sureda A, Velardi A, Madrigal A, for the European Society for Blood and Marrow Transplantation (EBMT). Hematopoietic SCT in Europe: data and trends in 2012 with special consideration of pediatric transplantation. Bone Marrow Transplant. 2014:1-7.

Passweg JR, Baldomero H, Bader P, Bonini C, Cesaro S, Dreger P, Duarte RF, Dufour C, Kuball J, Farge-Bancel D, Gennery A, Kröger N, Lanza F, Nagler A, Sureda A, Mohty M, for the European Society for Blood and Marrow Transplantation (EBMT). Hematopoietic stem cell transplantation in Europe 2014: more than 40000 transplants annually. Bone Marrow Transplant. 2016:1-7.

Pentz RD, Alderfer MA, Pelletier W, Stegenga K, Haight AE, Hendershot KA, et al. Unmet needs of siblings of pediatric stem cell transplant recipients. Pediatrics. 2014;133(5):e1156-62.

Phipps S, Dunavant M, Lensing S, Rai SN. Acute health related quality of life in children undergoing stem cell transplant: II. Medical and demographic determinants. Bone Marrow Transplant. 2002;29:435-42.

Pulsipher MA, Levine JE, Hayashi RJ, Chan KW, Anderson P, Duerst R, et al. Safety and efficacy of allogeneic PBSC collection in normal pediatric donors: the pediatric blood and marrow transplant consortium experience (PBMTC) 1996-2003. Bone Marrow Transplant. 2005;35(4):361-7.

Smith FO, Reaman GH, Racadio JM. Hematopoietic cell transplantation in children with cancer: Springer; 2014.

Styczynski J, Balduzzi A, Gil L, Labopin M, Hamladji RM, Marktel S, et al. Risk of complications during hematopoietic stem cell collection in pediatric sibling donors: a prospective European Group for Blood and Marrow Transplantation Pediatric Diseases Working Party study. Blood. 2012;119(12):2935-42.

Tremolada M, Bonichini S, Pillon M, Messina C, Carli M. Quality of life and psychosocial sequelae in children undergoing hematopoietic stem-cell transplantation: a review. Pediatr Transplant. 2009;12:955-70.

Vogel R. The management of the sibling hematopoietic stem cell transplant donor. J Pediatr Oncol Nurs. 2011;28(6):336-43.

Wiener LS, Steffen-Smith E, Fry T, Wayne A. Hematopoeitic stem cell donation in children: a review of the sibling donor experience. J Psychosoc Oncol. 2007;25(1):45-66. 
Williams S, Green R, Morrison A, Watson D, Buchanan $\mathrm{S}$. The psychosocial aspects of donating blood stem cells: the sibling donor perspective. J Clin Apher. 2003;18(1):1-9.

\section{Transplantation Through the Ages: Teenage and Young Adults (TYA)}

Barfield R, Kodish E. Ethical considerations in pediatric hematopoietic stem-cell transplantation. Pediatr Hematopoietic Stem Cell Transplant. 2006:251-70.

Bayer SR, Alper MM, Penzias AS. The Boston Ivf handbook of infertility: a practical guide for practitioners who care for infertile couples: CRC Press. Florida; 2011.

Department of Health. Reference guide to consent for examination or treatment. In: Doh, editors. London; 2009

Desandes E, Bonnay S, Berger C, Brugieres L, Demeocq F, Laurence V, Sommelet D, Tron I, Clavel J, Lacour B. Pathways of care for adolescent patients with cancer in france from 2006 to 2007. Pediatr Blood Cancer. 2012;58:924-9.

Fan S-Y, Eiser C. Body image of children and adolescents with cancer: a systematic review. Body Image. 2009;6:247-56.

Forinder U, Posse E. A life on hold': adolescents' experiences of stem cell transplantation in a long-term perspective. J Child Health Care. 2008;12:301-13.

Gatta G, Zigon G, Capocaccia R, Coebergh JW, Desandes E, Kaatsch P, Pastore G, Peris-Bonet R, Stiller CA. Survival of european children and young adults with cancer diagnosed 1995-2002. Eur J Cancer. 2009;45:992-1005.

GMC. 0-18 Years: guidance for all doctors. In: Council, G. M, editor. London; 2007.

Gratwohl A, Baldomero H, Demirer T, Rosti G, Dini G, Ladenstein R, Urbano-Ispizua A. Hematopoetic stem cell transplantation for solid tumors in Europe. Ann Oncol. 2004;15:653-60.

Grinyer A. Young people living with cancer: implications for policy and practice. London: Mcgraw-Hill Education; 2007.

Grinyer A. Contrasting parental perspectives with those of teenagers and young adults with cancer: comparing the findings from two qualitative studies. Eur J Oncol Nurs. 2009;13:200-6.

Human Tissue Authority. Guidance to bone marrow and peripheral blood stem cell transplant teams and accredited assessors: HTA; 2015.

Kaufman M. Role of adolescent development in the transition process. Prog Transplant. 2006;16:286-90.

Kondryn HJ, Edmondson CL, Hill J, Eden TOB. Treatment non-adherence in teenage and young adult patients with cancer. Lancet Oncol. 2011;12:100-8.

Lassaletta A, Andión M, Garrido-Colino C, GutierrezCarrasco I, Echebarria-Barona A, Almazán F, LópezIbor B, Ortega-Acosta MJ. The current situation of adolescents with cancer in pediatric hematology- oncology units in Spain. Results of a national survey. Anales De Pediatria (Barcelona, Spain : 2003). 2013;78:268.E1-7.

Leiper AD. Late effects of total body irradiation. Arch Dis Child. 1995;72:382-5.

Levine J, Stern CJ. Fertility preservation in adolescents and young adults with cancer. J Clin Oncol. 2010;28:4831-41.

Long KA, Marsland AL. Family adjustment to childhood cancer: a systematic review. Clin Child Fam Psychol Rev. 2011;14:57-88.

Lowis S. Malignant disease and the adolescent. J Royal College Physicians. 2000;34:27-31.

Macleod KD, Whitsett SF, Mash EJ, Pelletier W. Pediatric sibling donors of successful and unsuccessful hematopoietic stem cell transplants (HSCT): a qualitative study of their psychosocial experience. J Pediatr Psychol. 2003;28:223-30.

Ministry of Health. The welfare of children in hospital, Platt report. In: Office, H. M. S. S, editors. London; 1959.

Moore C, Rauch P. Addressing parenting concerns of bone marrow transplant patients: opening (and closing) pandora's box. Bone Marrow Transplant. 2006;38:775-82.

National Institute for Health and Clinical Excellence. Children and young people with cancer. London: Nice; 2014.

Nicolussi A. Informed consent and minors. Ital J Pediatr. 2015;41:1-1.

Pot-Mees CC, Zeitlin H. Psychosocial consequences of bone marrow transplantation in children: a preliminary communication. J Psychosoc Oncol. 1987;5:73-81.

Quinn GP, Vadaparampil ST, Group, F. P. R. Fertility preservation and adolescent/young adult cancer patients: physician communication challenges. $\mathrm{J}$ Adolesc Health. 2009;44:394-400.

Rodgers C, Young A, Hockenberry M, Binder B, Symes L. The meaning of adolescents' eating experiences during bone marrow transplant recovery. J Pediatr Oncol Nurs. 2010;27:65-72.

Saito K, Suzuki K, Iwasaki A, Yumura Y, Kubota Y. Sperm cryopreservation before cancer chemotherapy helps in the emotional battle against cancer. Cancer. 2005;104:521-4.

Smith S, Davies S, Wright D, Chapman C. The experiences of teenagers and young adults with cancerresults of 2004 conference survey. Eur J Oncol Nurs. 2007;11:362-8.

Smith S, Vogel CL, Waterhouse K, Pettitt N, Beddard L, Oldham J, Hubber D, Simon S, Siddall J. A blueprint of care for teenagers and young adults with cancer. Guidelines for Health Professionals: London; 2012.

Stark D, Bielack S, Brugieres L, Dirksen U, Duarte X, Dunn S, Erdelyi DJ, Grew T, Hjorth L, Jazbec J, Kabickova E, Konsoulova A, Kowalczyk JR, Lassaletta A, Laurence V, Lewis I, Monrabal A, Morgan S, Mountzios G, Olsen PR, Renard M, Saeter G, Van Der Graaf WT, Ferrari A. Teenagers and young adults with cancer in Europe: from national programmes to a European integrated coordinated project. Eur J Cancer Care. 2016;25:419-27. 
Taddeo DM, Egedy MM, Frappier JYM. Adherence to treatment in adolescents: Paediatr Child Health. 2008;13(1):19-24.

Thomas D, Seymour J, O'brien T, Sawyer S, Ashley D. Adolescent and young adult cancer: a revolution in evolution? Intern Med J. 2006;36:302-7.

Transplant, B. S. B. M. Indications for HSCT in children Uk Paediatric BMT Group 2015, UK: BSBMT; 2015.

Wheeler R. Gillick or fraser? A plea for consistency over competence in children. BMJ. 2006;332:807.

Whelan J. Where should teenagers with cancer be treated? Eur J Cancer. 2003;39:2573-8.

Whiteson M. The Teenage Cancer Trust-advocating a model for teenage cancer services. Eur $\mathrm{J}$ Cancer. 2003;39:2688-93.

Wiener LS, Steffen-Smith E, Battles HB, Wayne A, Love CP, Fry T. Sibling stem cell donor experiences at a single institution. Psychooncology. 2008;17:304-7.

Wilkins KL, Woodgate RL. Supporting siblings through the pediatric bone marrow transplant trajectory: perspectives of siblings of bone marrow transplant recipients. Cancer Nurs. 2007;30:E29-34.

\section{Transplanting the Adult and the Older Adult: Nursing Considerations}

Almeida OP, Almeida SA. Short versions of the geriatric depression scale: a study of their validity for the diagnosis of a major depressive episode according to ICD-10 and DSM-IV. Int J Geriatr Psychiatry. 1999;14(10):858-65.

Artz AS, Chow S. Hematopoietic cell transplantation in older adults: deciding or decision-making? Bone Marrow Transplant. 2016;51(5):643-4.

Artz AS, Pollyea DA, Kocherginsky M, Stock W, Rich E, Odenike O, Zimmerman T, Smith S, Godley L, Thirman M, Daugherty C, Extermann M, Larson R, van Besien K. Performance status and comorbidity predict transplant-related mortality after allogeneic hematopoietic cell transplantation. Biol Blood Marrow Transplant. 2006;12(9):954-64.

Boyd CM, McNabney MK, Brandt N, Correa-deAraujuo R, Daniel M, Epplin J, Fried TR, Goldstein MK, Holmes HM, Ritchie CS, Shega JW. Guiding principles for the care of older adults with multimorbidity: an approach for clinicians: American Geriatrics Society expert panel on the care of older adults with multimorbidity. J Am Geriatr Soc. 2012;60(10):E1-E25.

Charlson ME, Pompei P, Ales KL, MacKenzie CR. A new method of classifying prognostic comorbidity in longitudinal studies: development and validation. J Chronic Dis. 1987;40:373-83.

D'Souza A, Pasquini M, Spellecy R. Is 'informed consent' an 'understood consent' in hematopoietic cell transplantation? Bone Marrow Transplant. 2015;50(1):10-4.
Elsawy M, Sorror ML. Up-to-date tools for risk assessment before allogeneic hematopoietic stem cell transplantation. Bone Marrow Transplant. 2016;51(10):1283-300.

Eichhorst B, Dreyling M, Robak T, Montserrat E, Hallek M. Chronic lymphocytic leukemia: ESMO Clinical Practice Guidelines for diagnosis, treatment and follow-up. Ann Oncol. 2011;22(Suppl 6):vi50-4.

Extermann M, Aapro M, Bernabei R, Cohen HJ, Droz JP, Lichtman S, Mor V, Monfardini S, Repetto L, Sørbye L, Topinkova E. Task Force on CGA of the International Society of Geriatric Oncology. Use of comprehensive geriatric assessment in older cancer patients: recommendations from the task force on CGA of the International Society of Geriatric Oncology (SIOG). Crit Rev Oncol Hematol. 2005;55(3):241-52.

Folstein MF, Folstein SE, McHugh PR. Mini-mental state: a practical method for grading the cognitive state of patients for the clinician. J Psychiatr Res. 1975;12:189-98.

Graf C. The Lawton instrumental activities of daily living scale. AJN. 2008;108(4):52-62.

Greene MG, Adelman RD. Physician-older patient communication about cancer. Patient Educ Couns. 2003;50(1):55-60.

Guigoz Y. The Mini Nutritional Assessment (MNA) review of the literature: what does it tell us? J Nutr Health Aging. 2006;10:466-87.

Karnofsky DA, Burchenal JH. The clinical evaluation of chemotherapeutic agents in cancer. In: MacLeod $\mathrm{CM}$, editor. Evaluation of chemotherapeutic agents. New York: Columbia Univ Press; 1949. p. 191-205.

Kenis C, Bron D, Libert Y, Decoster L, Van Puyvelde K, Scalliet P, Cornette P, Pepersack T, Luce S, Langenaeken C, Rasschaert M, Allepaerts S, Van Rijswijk R, Milisen K, Flamaing J, Lobelle JP, Wildiers $H$. Relevance of a systematic geriatric screening and assessment in older patients with cancer: results of a prospective multicentric study. Ann Oncol. 2013;24(5):1306-12.

Kruizenga HM, Seidell JC, de Vet HC, Wierdsma NJ, van Bokhorst-de van der Schueren MA. Development and validation of a hospital screening tool for malnutrition: the Short Nutritional Assessment Questionnaire (SNAQ). Clin Nutr. 2005;24:75-82.

Lam WY, Fresco P. Medication adherence measures: an overview. Biomed Res Int. 2015:217047. Published online 11 Oct 2015. doi:https://doi. org/10.1155/2015/217047.

Mamdani H, Santos CD, Konig H. Treatment of acute myeloid leukemia in elderly patients-a therapeutic dilemma. J Am Med Dir Assoc. 2016;17(7):581-7.

Mahoney FI, Barthel DW. Functional evaluation: the Barthel Index. Md State Med J. 1965:1461-5.

Mor V, Laliberte L, Morris JN, Wiemann M. The Karnofsky performance status scale. Cancer. 1984:2002-7.

National Cancer Institute. MDS, median age 71 years, Sekeres MA. The epidemiology of myelodysplastic syndromes. Hematol Oncol Clin North Am 2010. 2003;24(2):287-94. 
Pallis AG, Wedding U, Lacombe D, Soubeyran P, Wildiers $\mathrm{H}$. Questionnaires and instruments for a multidimensional assessment of the older cancer patient: what clinicians need to know? Eur J Cancer. 2010;46:1019-25.

Palumbo A, Anderson K. Multiple myeloma. N Engl J Med. 2011;364:1046-60. https://doi.org/10.1056/ NEJMra1011442.

Palumbo A, Bringhen S, Mateos MV, Larocca A, Facon T, Kumar SK, Offidani M, McCarthy P, Evangelista A, Lonial S, Zweegman S, Musto P, Terpos E, Belch A, Hajek R, Ludwig H, Stewart AK, Moreau P, Anderson K, Einsele H, Durie BG, Dimopoulos MA, Landgren O, San Miguel JF, Richardson P, Sonneveld P, Rajkumar SV. Geriatric assessment predicts survival and toxicities in elderly myeloma patients: an International Myeloma Working Group report. Blood. 2015;125(13):2068-74.

Posma ER, van Weert JC, Jansen J, Bensing JM. Older cancer patients' information and support needs surrounding treatment: an evaluation through the eyes of patients, relatives and professionals. BMC Nurs. 2009;8:1.

Puts MT, Tu HA, Tourangeau A, Howell D, Fitch M, Springall E, Alibhai SM. Factors influencing adherence to cancer treatment in older adults with cancer: a systematic review. Ann Oncol. 2014;25(3):564-77.

Randall J, Keven K, Atli T, Ustun C. Process of allogeneic hematopoietic cell transplantation decision making for older adults. Bone Marrow Transplant. 2016;51(5):623-8.

Saliba D, Elliott M, Rubenstein LZ, Solomon DH, Young RT, Kamberg CJ, Roth C, MacLean CH, Shekelle PG, Sloss EM, Wenger NS. The vulnerable elders survey: a tool for identifying vulnerable older people in the community. J Am Geriatr Soc. 2001;49:1691-9.

Sattar S, Alibhai SM, Wildiers H, Puts MT. How to implement a geriatric assessment in your clinical practice. Oncologist. 2014;19(10):1056-68.

Schenker Y, Fernandez A, Sudore R, Schillinger D. Interventions to improve patient comprehension in informed consent for medical and surgical procedures: a systematic review. Med Decis Making. 2011;31(1):151-73.
Sekeres MA. The epidemiology of myelodysplastic syndromes. Hematol Oncol Clin North Am. 2010;24(2):287-94.

Sheikh JA, Yesavage JA. Geriatric Depression Scale (GDS): recent findings and development of a shorter version. In: Brink TL, editor. Clinical gerontology: a guide to assessment and intervention. New York: Howarth Press; 1986.

Siegel RL, Miller KD, Jemal A. Cancer statistics, 2015. CA Cancer J Clin. 2015;65:5-29.

Smith A, Howell D, Patmore R, Jack A, Roman E. Br J Cancer. 2011;105(11):1684-92.

Sorror ML, Maris MB, Storb R, Baron F, Sandmaier BM, Maloney DG, Storer B. Hematopoietic cell transplantation (HCT)-specific comorbidity index: a new tool for risk assessment before allogeneic HCT. Blood. 2005;106(8):2912-9.

Soubeyran P, Bellera C, Goyard J, et al. Validation of the G8 screening tool in geriatric oncology: the ONCODAGE project. J Clin Oncol. 2011;29(Suppl):abstr 9001.

Stratton RJ, Hackston A, Longmore D, Dixon R, Price S, Stroud M, et al. Malnutrition in hospital outpatients and inpatients: prevalence, concurrent validity and ease of use of the "malnutrition universal screening tool" ("MUST") for adults. Br J Nutr. 2004;92(05):799-808.

Valentijn SA, van Boxtel MP, van Hooren SA, Bosma H, Beckers HJ, Ponds RW, Jolles J. Change in sensory functioning predicts change in cognitive functioning: results from a 6-year follow-up in the maastricht aging study. J Am Geriatr Soc. 2005;53(3):374-80.

Van Cleave JH, Kenis C, Sattar S, Jabloo VG, Ayala AP, Puts M. A research agenda for gero-oncology nursing. Semin Oncol Nurs. 2016 Feb;32(1):55-64.

Williams AM, Zent CS, Janelsins MC. What is known and unknown about chemotherapy-related cognitive impairment in patients with haematological malignancies and areas of needed research. Br J Haematol. 2016;174(6):835-46.

WHO. Definition of an older or elderly person. Geneva, Switzerland: World Health Organisation; 2010. Accessed 14 Apr 2017. http://www.who.int/healthinfo/survey/ageingdefnolder/en/index.html.

Open Access This chapter is licensed under the terms of the Creative Commons Attribution 4.0 International License (http://creativecommons.org/licenses/by/4.0/), which permits use, sharing, adaptation, distribution and reproduction in any medium or format, as long as you give appropriate credit to the original author(s) and the source, provide a link to the Creative Commons license and indicate if changes were made.

The images or other third party material in this chapter are included in the chapter's Creative Commons license, unless indicated otherwise in a credit line to the material. If material is not included in the chapter's Creative Commons license and your intended use is not permitted by statutory regulation or exceeds the permitted use, you will need to obtain permission directly from the copyright holder.

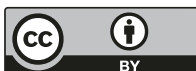

